ZUMJ-1903-1180 (R1)

DOI

10.21608/zumj.2019.11362.1180

ORIGINAL ARTICLE

\title{
Relationship between blood pressure indices and severity of coronary atherosclerosis
}

\author{
Salwa Mohammed Mohammed Ghoniem ${ }^{1}$, Hanan Ibrahim Radwan ${ }^{1}$, Hisham Mohamed \\ Elamin Naas ${ }^{1}$ \\ 1: Faculty of Medicine, Zagazig University, Department of Cardiology, Sharkia Egypt
}

\author{
* Corres ponding author: \\ Hisham Mohamed Elamin \\ Naas \\ Faculty of Medicine, \\ Zagazig University, \\ Department of Cardiology, \\ Sharkia Egypt \\ E.mail : \\ hmelamin@yahoo.com
}

Submit Date

2019-08-16

Revise Date 2019-09-08

Accept Date 2019-09-10
ABSTRACT
Introduction: Blood pressure assessment is important for the evaluation of cardio-vascular disease and can be measured both invasively and noninvasively. Conventional noninvasive brachial blood pressure measurement has its own limitations. This study aimed to assess the relation between blood pressure indices and atherosclerotic burden in patients with obstructive coronary artery disease. Methods: A Cross sectional study was conducted at Cardiology Department of the Zagazig University Hospitals during the period from April 2018 to October 2018, This study included 90 consecutive stable patients with evidence of obstructive CAD as detected by elective coronary angiography. Patients were divided into 2 groups due to SYNTAX scores. Group I : >22 SYNTAX score, Group II : <22 SYNTAX score. Results: There is a significant positive correlation between SYNTAX score with invasive BP parameters (SBP, PP, FSP, FPP and PI) Although there is significant negative correlations between SYNTAX score with invasive DBP and FDP. LDL, non-invasive DBP, invasive central aortic SBP, DBP, PP, FSP, FDP, FPP, PI were significantly independently associated with high SYNTAX score. Conclusion: Invasive central aortic pressures were more predictive than peripheral pressures for the extent of coronary atherosclerosis which is identified by the presence of high SYNTAX Score. A definite significant association between both low DBP \& high dynamic pulsatile components of central aortic pressure (SBP, FSP and pulsility indices ) and high SYNTAX Score in stable patients with obstructive CAD

Keywords; blood pressure; coronary atherosclerosis; Fractional Diastolic Pressure; Blood Pressure indices.

\section{INTRODUCTION}

lthough the established risk factors such A as smoking, high blood cholesterol levels and hypertension have shown to be associated with the development of coronary artery disease (CAD), defining the role of "blood pressure indices" for predicting CAD remains clinically challenging. These indices are calculated from systolic blood pressure (SBP) \& diastolic blood pressures (DBP),i.e. the mean Arterial Pressure (MAP), where [ $\mathrm{MAP}=1 / 3$ systolic pressure $+2 / 3$ diastolic pressure ]. And pulse pressure (PP) (which is the difference between SBP \& DBP). Beside that we normalized the systolic and diastolic pressures to the mean arterial pressure for other indices calculation, i.e. the fractional systolic pressure (FSP), the fractional diastolic pressure (FDP), the fractional pulse pressure (FPP) and lastly the pulsatility index (PI) $[1,2]$.

Blood pressure (BP) assessment is an important part of the evaluation of cardiovascular disease and can be measured both invasively and noninvasively. Conventional noninvasive brachial blood pressure (bBP) 
measurement has its own limitations. So brachial blood pressure (bBP) is inaccurate surrogates of the aortic pressure especially diastolic (DBP) and mean (MBP), so invasive monitoring of aortic pressure are superior to noninvasive method emphasizing the need for central BP recognition [3].

The central aortic pressure represent the real hemodynamic stress imposed on the heart, the coronary circulation, the cerebral vessels, and the renal microcirculation [4].

Recently, central BP and arterial stiffness have been found to be more relevant than peripheral pressures in the pathogenesis of CVD [5].

Central pulse pressure more predictive than peripheral PP while no difference for SBP was observed [6].

Advantages of central Aortic pressures measurement [3]:

1- Aortic MAP is directly measured while brachial MBP is calculated, so brachial MBP higher than the measured aortic MBP.

2- Aortic DBP, which is closely approximated by invasive brachial diastolic, differs markedly from DBP measured by cuff method.

3- Brachial systolic BP is higher than aortic SBP a difference that diminishes with aging due to reduction of the pulse pressure amplification.

Central BP indices are found to be independently associated with subclinical CVD and adverse CV events in the general population and patients with several $\mathrm{CV}$ risk factors or diseases [7].

The pulsatile components of blood pressure (SBP, PP, pulsility indices) has been found to be more important in the prediction of future cardiovascular adverse events in comparison to the steady-state component (mean blood pressure) [8].

Several studies have found a relationship between central aortic systolic or PP and extent of coronary atherosclerosis, and intima-media thickness [4].

The aim of this work was to assess the relationship between blood pressure indices and atherosclerotic burden in patients with obstructive coronary artery disease.

\section{METHODS}

A Cross sectional study was carried out at Cardiology Department of the Zagazig University Hospitals from April 2018 to October 2018, on patients with symptoms of stable chronic angina underwent elective coronary angiography. This study included 90 subjects were divided into 2 groups due to SYNTAX scores. Group I : >22 SYNTAX score, were categorized as intermediate and high score. Group II : <22 SYNTAX score, were categorized as low score.

\section{Inclusion criteria}

- Age $>18$ years.

- Patients with symptoms of chronic stable angina undergoing elective coronary angiography.

\section{Exclusion criteria}

- Patients with acute coronary syndrome.

- Renal impairment with serum creatinine > 1.5 mg.

- Unable to obtain a full study of the coronary arteries.

- No evidence of significant coronary artery disease.

\section{Ethical Clearance}

Written Informed consent was taken from the subjects participated in this study. the study was approved by the research ethical committee of Faculty of Medicine, Zagazig University. The work has been carried out in accordance with The Code of Ethics of the World Medical Association (Declaration of Helsinki) for studies involving humans.

Methods : Each patient was subjected to:

\section{(A) Full history taking with special emphasis on:}

1. Demographic criteria including Age, Sex, and Body Mass Index (BMI).

2. A detailed medical and cardiac history including cardio-vascular risk factors:

- History of smoking (number of cigarettes smoked per day and duration of smoking).

- History of hypertension diagnosed and treated with medication, diet and/or exercise.

- History of stroke, old MI, PVD.

- Family history of premature CAD was defined as early $\mathrm{CAD}$ in first degree relatives (male $<55$, female $<65$ ).

- History of Diabetes. 
- History of Dyslipidemia.

(B) Physical Examination:

Complete clinical examination including:

- Pulse (peripheral \&central), Blood pressure, Edema of lower limb.

- Chest \& abdominal examination.

- Cardiac examination including inspection, palpation and auscultation.

In blood pressure measurement, Patients should be seated comfortably in a quiet room for $5 \mathrm{~min}$ before. Sphygmomanometered brachial blood pressure are the preferred method for measuring BP in the doctor's office. Three BP measurements should be recorded, 1-2 min apart, the third only if the first two measurement readings differ by $>10$ $\mathrm{mmHg}$. $\mathrm{BP}$ is recorded as the average of the last two BP readings. The cuff should be positioned on arm at the level of the heart, we hear Korotkoff sounds to identify SBP and DBP, respectively.

During coronary angiography, we measured invasive arterial pressure with intravascular cannula by placing its needle in an artery (radial, femoral, dorsalis pedis or brachial). The cannula must be connected to a sterile, fluid-filled system, which is connected to an electronic pressure transducer. Patients with invasive arterial monitoring require very close supervision, as there is a danger of severe bleeding if the line becomes disconnected.

Once Systolic and Diastolic blood pressures recorded, Other blood pressure indices can be calculated as following :

Mean BP was calculated : MAP $=[\mathrm{SBP}+$ ( 2 DBP) $] \backslash 3$.

- Pulse pressure is the difference between the measured systolic and diastolic pressures [PP $=\mathrm{SBP}-\mathrm{DBP}]$.

- The pulsatility index [PI = ratio of PP / DBP].

- Fractional pulse pressure [FPP = PP / MAP]

- Fractional systolic pressure $[\mathrm{FSP}=\mathrm{SBP} /$ MAP]

- Fractional diastolic pressure $[\mathrm{FDP}=\mathrm{DBP} /$ MAP 1

(C) Laboratory investigations :

- Complete blood count (CBC).

- Serum creatinine.

- Fasting lipid Profile (TG, HDL cholesterol, LDL cholesterol, Total cholesterol).
- Random Blood Sugar.

(D) ECG : Conventional, standard 12 leads ECG.

(E) Echo: to assess LVEF, The Simpson method enables to determine the volume of the left ventricle. After the calculation of enddiastolic EDV as well as end-systolic volumes ESV, ejection fraction calculated by using the following formula : EF = EDV-ESV/EDV $\mathbf{X}$ 100.

\section{(F) Coronary angiography}

All patients underwent Coronary angiography. Coronary anatomy was examined by two experienced cardiologists and according to the evaluations result, the same opinion was reached. The SYNTAX score for every patient was calculated by all coronary lesions scores, to differentiate patients with high and intermediate risk score, from those with low risk score, using the SYNTAX score algorithm.

\section{Statistical analysis}

Data were collected, tabulated and analyzed by SPSS 20, software for Windows. The level of significance was $<0.05$.

\section{RESULTS}

Table (1), showed that there was no statistical significant difference between the studied groups regarding age, sex and BMI. Table (2), showed that there was no statistical significant difference between the studied groups regarding risk factors, $\mathrm{H} \backslash \mathrm{O} \mathrm{MI}$, Stroke, PVD or medications. Table (3), showed that for Non-invasive brachial blood pressure, patients with high syntax score have significantly higher SBP, FSP,PP, FPP \& PI values and significantly lower DBP, MAP \& FDP values. Table (4), showed that for invasive blood pressure, patients with high syntax score have significantly higher SBP, FSP, PP, FPP \& PI values and significantly lower DBP\& FDP values. Table (5), showed that there was a statistical significant difference between the studied groups regarding LDL cholesterol and SYNTAX score (patients with high syntax score). Table (6), showed that there was a significant positive correlations between SYNTAX score with SBP, PP, FSP, FPP, PI and LDL and a negative correlations between SYNTAX score with DBP and FDP. 
Table 1. Demographic data of the studied groups.

\begin{tabular}{|c|c|c|c|c|c|c|}
\hline & & $\begin{array}{l}\text { All patients } \\
\quad(n=90)\end{array}$ & $\begin{array}{l}\text { Intermediatel } \\
\text { High SYNTAX } \\
\qquad(n=17)\end{array}$ & $\begin{array}{c}\text { Low SYNTAX } \\
(\boldsymbol{n}=73)\end{array}$ & $t / \chi^{2}$ & $p$ \\
\hline \multicolumn{2}{|c|}{$\begin{array}{c}\text { Age (years) } \\
\text { Mean } \pm S D\end{array}$} & $48.51 \pm 10.26$ & $58.51 \pm 10.26$ & $53.26 \pm 9.72$ & 1.026 & .093 \\
\hline \multirow[t]{2}{*}{ Sex } & Male & $66(73.3 \%)$ & $13(76.5 \%)$ & $53(72.6 \%)$ & \multirow[t]{2}{*}{.862} & \multirow[t]{2}{*}{.163} \\
\hline & Female & $24(26.7 \%)$ & $4(23.5 \%)$ & $20(27.4 \%)$ & & \\
\hline \multicolumn{2}{|c|}{$\begin{array}{c}\boldsymbol{B M I}\left(\mathrm{kg} / \mathrm{m}^{2}\right) \\
\text { Mean } \pm S D\end{array}$} & $54.11 \pm 6.23$ & $27.21 \pm 3.6$ & $28.07 \pm 5.8$ & .916 & .102 \\
\hline
\end{tabular}

Table 2. Comparison of risk factors and medications between the two studied groups.

\begin{tabular}{|c|c|c|c|c|c|}
\hline Variable & $\begin{array}{c}\text { All patients } \\
\quad(n=90)\end{array}$ & $\begin{array}{c}\text { Intermediate/High } \\
\text { SYNTAX } \\
(n=17)\end{array}$ & $\begin{array}{c}\text { Low SYNTAX } \\
\quad(n=73)\end{array}$ & $\chi^{2}$ & $P$ \\
\hline HTN & $48(53.3 \%)$ & $7(41.2 \%)$ & $41(56.2 \%)$ & .946 & .113 \\
\hline$D M$ & $36(40 \%)$ & $5(29.4 \%)$ & $31(42.5 \%)$ & 1.320 & .082 \\
\hline Smoking & $29(32.2 \%)$ & $6(35.3 \%)$ & $23(31.5 \%)$ & .861 & .142 \\
\hline Hyperlipidemia & $23(25.6 \%)$ & $4(23.5 \%)$ & $19(26 \%)$ & .813 & .216 \\
\hline MI & $20(22.2 \%)$ & $8(47.1 \%)$ & $12(16.4 \%)$ & 2.868 & .090 \\
\hline Stroke & $6(6.7 \%)$ & $2(11.8 \%)$ & $4(5.5 \%)$ & .316 & .574 \\
\hline$P V D$ & $10(11.1 \%)$ & $2(11.8 \%)$ & $8(11 \%)$ & .039 & .987 \\
\hline Aspirin & $87(96.7 \%)$ & $16(94.1 \%)$ & $61(83.6 \%)$ & \multirow[t]{4}{*}{.749} & \multirow[t]{4}{*}{.261} \\
\hline $\begin{array}{c}A C E I \text { or } \\
A R B\end{array}$ & $28(31.1 \%)$ & $4(23.5 \%)$ & $24(32.9 \%)$ & & \\
\hline$B B$ & $61(67.8 \%)$ & $12(70.6 \%)$ & $49(67.1 \%)$ & & \\
\hline Statin & $51(56.7 \%)$ & $9(52.9 \%)$ & $42(57.5 \%)$ & & \\
\hline
\end{tabular}


Table 3. Non-invasive brachial blood pressure between the two studied groups.

\begin{tabular}{|c|c|c|c|c|c|}
\hline Variable & $\begin{array}{l}\text { All patients } \\
\qquad(n=90)\end{array}$ & $\begin{array}{c}\text { /High SYNTAX } \\
(n=17)\end{array}$ & $\begin{array}{c}\text { Low SYNTAX } \\
\qquad(n=73)\end{array}$ & $t$ & $P$ \\
\hline $\begin{array}{c}\boldsymbol{S B P}(m m \mathrm{Hg}) \\
\text { Mean } \pm S D\end{array}$ & $128.73 \pm 8.92$ & $136.33 \pm 8.05$ & $126.83 \pm 8.6$ & 3.131 & .003 \\
\hline $\begin{array}{c}\boldsymbol{D B P}(m m \mathrm{Hg}) \\
\text { Mean } \pm S D\end{array}$ & $72.16 \pm 7.77$ & $63.33 \pm 2.79$ & $74.67 \pm 6.63$ & 4.982 & .000 \\
\hline $\begin{array}{c}\boldsymbol{M B P}(m m \mathrm{Hg}) \\
\text { Mean } \pm \text { SD }\end{array}$ & $91.18 \pm 5.22$ & $87.67 \pm 2.42$ & $92.06 \pm 5.38$ & 2.371 & .022 \\
\hline $\begin{array}{c}\boldsymbol{P P}(m m \mathrm{Hg}) \\
\text { Mean } \pm S D\end{array}$ & $56.33 \pm 12.99$ & $73.0 \pm 9.69$ & $52.17 \pm 10.08$ & 5.584 & .000 \\
\hline $\begin{array}{c}\boldsymbol{F S P} \\
\text { Mean } \pm S D\end{array}$ & $1.41 \pm .104$ & $1.55 \pm .066$ & $1.38 \pm .079$ & 6.114 & .000 \\
\hline $\begin{array}{c}\boldsymbol{F D P} \\
\text { Mean } \pm S D\end{array}$ & $0.793 \pm .052$ & $.723 \pm .033$ & $.81 \pm .039$ & 6.114 & .000 \\
\hline $\begin{array}{c}\boldsymbol{F P P} \\
\text { Mean } \pm S D\end{array}$ & $0.622 \pm .156$ & $.832 \pm .099$ & $.057 \pm .119$ & 6.114 & .000 \\
\hline $\begin{array}{c}\boldsymbol{P I} \\
\text { Mean } \pm S D\end{array}$ & $0.801 \pm 0.255$ & $1.16 \pm .186$ & $.711 \pm .181$ & 6.596 & .000 \\
\hline
\end{tabular}

Table 4. Invasive blood pressure indices of the studied groups.

\begin{tabular}{|c|c|c|c|c|c|}
\hline Variable & $\begin{array}{l}\text { All patients } \\
\qquad(n=90)\end{array}$ & $\begin{array}{c}\text { High SYNTAX } \\
(n=17)\end{array}$ & $\begin{array}{c}\text { Low SYNTAX } \\
\quad(n=73)\end{array}$ & $t$ & $\boldsymbol{P}$ \\
\hline $\begin{array}{c}\boldsymbol{S B P}(m m \mathrm{Hg}) \\
\text { Mean } \pm S D\end{array}$ & $126.73 \pm 9.16$ & $134.44 \pm 7.42$ & $124.81 \pm 8.59$ & 3.085 & .004 \\
\hline $\begin{array}{c}\mathrm{DBP}(\mathrm{mm} \mathrm{Hg}) \\
\text { Mean } \pm S D\end{array}$ & $71.29 \pm 7.29$ & $66.78 \pm 8.57$ & $72.97 \pm 6.49$ & 2.399 & .021 \\
\hline $\begin{array}{c}\operatorname{MBP}(m m H g) \\
\text { Mean } \pm S D\end{array}$ & $90.07 \pm 5.59$ & $89.33 \pm 5.91$ & $90.25 \pm 5.58$ & .436 & .665 \\
\hline $\begin{array}{l}\boldsymbol{P P}(m m \mathrm{Hg}) \\
\text { Mean } \pm S D\end{array}$ & $55.0 \pm 12.04$ & $67.67 \pm 12.07$ & $51.83 \pm 9.87$ & 4.120 & .000 \\
\hline $\begin{array}{c}\boldsymbol{F S P} \\
\text { Mean } \pm S D\end{array}$ & $1.41 \pm .098$ & $1.51 \pm .109$ & $1.38 \pm .078$ & 3.974 & .000 \\
\hline $\begin{array}{c}\boldsymbol{F D P} \\
\text { Mean } \pm S D\end{array}$ & $.795 \pm .049$ & $.745 \pm .055$ & $.808 \pm .039$ & 3.974 & .000 \\
\hline $\begin{array}{c}\boldsymbol{F P P} \\
\text { Mean } \pm S D\end{array}$ & $.614 \pm .146$ & $.764 \pm .164$ & $.577 \pm .116$ & 3.974 & .000 \\
\hline $\begin{array}{c}\boldsymbol{P I} \\
\text { Mean } \pm S D\end{array}$ & $.786 \pm .242$ & $1.045 \pm .305$ & $.722 \pm .177$ & 4.196 & .000 \\
\hline
\end{tabular}


Table 5. Laboratory parameters between the two studied groups.

\begin{tabular}{|c|c|c|c|c|}
\hline Variable & $\begin{array}{c}\text { Intermediate/High } \\
\text { SYNTAX } \\
(n=17)\end{array}$ & $\begin{array}{l}\text { Low SYNTAX } \\
(n=73)\end{array}$ & $t$ & $P$ \\
\hline $\begin{array}{c}\boldsymbol{H b}(g / d L) \\
\text { Mean } \pm S D\end{array}$ & $12.31 \pm 1.13$ & $12.88 \pm 1.69$ & 1.083 & .288 \\
\hline $\begin{array}{c}T L C(m g / d L) \\
\text { Mean } \pm S D\end{array}$ & $6.72 \pm 4.83$ & $7.16 \pm 2.99$ & .467 & .644 \\
\hline $\begin{array}{c}\boldsymbol{P L T}(m g / d L) \\
\text { Mean } \pm S D\end{array}$ & $293.95 \pm 96.26$ & $351.88 \pm 86.95$ & 1.492 & .147 \\
\hline $\begin{array}{c}\boldsymbol{R B S}(m g / d L) \\
\text { Mean } \pm S D\end{array}$ & $120.63 \pm 23.9$ & $123.12 \pm 33.81$ & .126 & .855 \\
\hline $\begin{array}{c}T C(m g / d L) \\
\text { Mean } \pm S D\end{array}$ & $206.4 \pm 73.69$ & $195.03 \pm 57.1$ & .625 & .480 \\
\hline $\begin{array}{l}\boldsymbol{T G}(m g / d L) \\
\text { Mean } \pm S D\end{array}$ & $174.03 \pm 17.22$ & $162.94 \pm 21.28$ & .159 & .737 \\
\hline $\begin{array}{l}\boldsymbol{L D L}(m g / d L) \\
\text { Mean } \pm S D\end{array}$ & $152.31 \pm 45.42$ & $125.36 \pm 38.17$ & 2.694 & .024 \\
\hline $\begin{array}{c}\boldsymbol{H D L}(m g / d L) \\
\text { Mean } \pm S D\end{array}$ & $43.29 \pm 9.23$ & $44.36 \pm 11.64$ & .001 & .973 \\
\hline $\begin{array}{c}\text { Serum creatinine }(\mathrm{mg} / \mathrm{dL}) \\
\text { Mean } \pm S D\end{array}$ & $0.82 \pm 0.17$ & $0.69 \pm 0.23$ & .166 & .763 \\
\hline $\begin{array}{c}\boldsymbol{E F}(\%) \\
\text { Mean } \pm S D\end{array}$ & $57 \pm 2.36$ & $55.41 \pm 1.57$ & 1.003 & .130 \\
\hline $\begin{array}{l}\text { SYNTAX score } \\
\text { Mean } \pm S D\end{array}$ & $26.82 \pm 3.69$ & $6.57 \pm 3.91$ & 6.325 & $<0.001$ \\
\hline
\end{tabular}


Table 6. Correlation of SYNTAX score with demographic and non-invasive BP parameters.

\begin{tabular}{|c|c|c|}
\hline Variable & $r$ & $P$ \\
\hline Age & .046 & .531 \\
\hline Male & .006 & .932 \\
\hline BMI & .208 & .380 \\
\hline DBP & .440 & $.002 * *$ \\
\hline MBP & -.506 & $.000 * *$ \\
\hline$P P$ & -.239 & .114 \\
\hline FSP & .597 & $.000 * *$ \\
\hline FDP & .605 & $.000 * *$ \\
\hline FPP & $\mathbf{. 6 0 5}$ & $.000 * *$ \\
\hline$P I$ & .605 & $.000 * *$ \\
\hline TC & .624 & $.000 * *$ \\
\hline TG & .033 & .890 \\
\hline LDL & .374 & .105 \\
\hline HDL & .228 & $.019 *$ \\
\hline$E F$ & .148 & .532 \\
\hline Creatinine & .336 & .147 \\
\hline & .097 & .684 \\
\hline
\end{tabular}

\section{DISCUSSION}

SYNTAX score has been identified as an independent predictor of mortality and major adverse cardiac diseases. The severity of the $\mathrm{CAD}$ as detected by coronary angiography can be estimated using the SYNTAX score. SYNTAX score was associated with the severity of atherosclerosis in the ascending aorta. Patients with a high SYNTAX score of 33 or more had an approximately 5-fold higher chance of severe atherosclerosis in the ascending aorta than those with low score of 22 or less [9].

Central aortic BP indices are emerging risk factors in the pathogenesis of CVD. Since atherosclerosis associated with CAD are closely related to cardiovascular mortality and morbidity. Therefore, investigated the relationship between $\mathrm{BP}$ indices and the extent of coronary atherosclerosis in unselected patients with angiographically confirmed coronary artery disease, quantified by SYNTAX Score. A total of 90 patients were included in our study. The mean age of the patients was $48.5 \pm 10.26$ years. 66 $(73.3 \%)$ were male. $17(18.9 \%)$ patients had a SYNTAX score $\geq 22$. When comparing low SYNTAX score patients with intermediatelhigh SYNTAX score patients, regarding the age, sex or BMI no significant difference was found between the two groups. These results were in agreement with the studies of Durmuş et al. [10] and Senthong et al. [11] . who reported that there was no significant statistical difference between studied groups regarding age, sex and BMI.

LDL levels were higher in the high SYNTAX score $(\geq 22)$ group compared to the a low SYNTAX score $(<22)$ group which in agreement with the results of Durmuş et al. [10]. However, Senthong et al. [11] found that LDL was lower in high SYNTAX Score 
group compared to high/intermediate SYNTAX Score groups without statistical significant.

We found significant positive or direct association between the dynamic pulsatile components of central aortic pressures [ SBP , FSP, PP,FPP \& PI ] and severity of CAD while DBP and FDP indices were inversely correlated with high SYNTAX score. However, the mean blood pressure which represented the steady-state component of BP did not show any definite relation with severity of $\mathrm{CAD}$, this in agreement with the study of Cho et al [12] found that only invasively assessed aortic SBP and pulsility indices (PP, FPP and PI) were significantly correlated with Gensini score, but non invasively assessed (NIA) indices of aortic pressure were not correlated. . NIA aortic PP underestimated IA aortic PP. Study reported by Jankowski et al concluded that central aortic BP indices are not correlated with coronary atherosclerosis severity in patients with left ventricular systolic dysfunction $\mathrm{EF}<50 \%$. Their results were discordant with our finding as our study included only patients with normal EF\%, where reduced left ventricular ejection may affect the BP.

We found that brachial DBP using cuff method higher than invasive central aortic DBP. Our results are in concordance with those of Jankowski et al.[13], who showed that noninvasive brachial DBP as was much higher than invasive DBP in the descending aorta. In contrast, the difference between brachial and aortic diastolic pressures was $<1$ $\mathrm{mm} \mathrm{Hg}$ when these pressures were measured invasively and simultaneously. Regarding diastolic blood pressure our study showed significant negative correlation between DBP \& FDP levels and coronary atherosclerosis severity by the SYNTAX Score in patients with stable CAD. Lower absolute and relative DBP level to mean BP (FDP) were independent predictors of higher SYNTAX score .

Our results are concordant with the study of Senthong et al. [11] who reported that DBP $<60 \mathrm{mmHg}$ was associated with myocardial ischemia, subclinical myocardial damage and adverse cardiovascular events.
Also, Stewart [15] found that lowering $\mathrm{DBP}<90 \mathrm{mmHg}$ was associated increased risk of myocardial infarction. Nakayama et al [14], showed that low FDP, not FSP, was related independently to CAD risk. Analysis of INVEST study, the J-shaped relationship was noted between BP particularly for DBP (119/84-mmHg) and adverse cardiovascular events [4].

So, our study provided additional support that patients with obstructive CAD intensive treatment of hypertension with severe reduction in DBP $<60 \mathrm{mmHg}$ may reduce coronary perfusion pressure and precipitate subclinical myocardial damage that may facilitate the development of severe coronary artery atherosclerotic burdens.

\section{CONCLUSION}

Invasive central aortic pressures were more predictive than peripheral pressures for the extent of coronary atherosclerosis which is identified by the presence of high SYNTAX Score. A definite significant association between both low DBP \& high dynamic pulsatile components of central aortic pressure (SBP, FSP and pulsility indices ) and high SYNTAX Score in stable patients with obstructive CAD.

Conflict of interest: Nothing to declare Financial disclosure: Nothing to declare REFERENCES

1. Klabunde RE. Cardiovascular Physiology Concepts - Mean Arterial Pressure. Archived from the original on 2009-10-04. Retrieved 2007; 2008-09-29.

2. Nakayama Y, Hayashi T, Yoshimaru K, Tsumura K, Ueda H. Low fractional diastolic pressure in the ascending aorta increased the risk of coronary heart disease. J Hum Hypertens 2002; 16:837-841.

3. Karamanoglu M, O'Rourke MF, Avolio AP, Kelly RP. An analysis of the relationship between central aortic and peripheral upper limb pressure waves in man. Eur Heart J. 1993 ;14(2):160-167.

4. Roman M.J., Devere ux R.B., Kizer J.R., Lee E.T., Galloway J.M., Ali T. Central pressure more strongly relates to vascular disease and outcome than does brachial pressure: the Strong Heart Study. Hypertension. Jul 2007; 50 (1):197-203.

5. Laurent S., Cockcroft J., Van Bortel L., Boutouyrie P., Giannattasio C., Hayoz D. 
Expert consensus document on arterial stiffness: Methodological issues and clinical applications. Eur Heart J 2006; 27:2588-605.

6. Vlachopoulos C, Aznaouridis K, Stefanadis C. Prediction of cardiovascular events and all-cause mortality with arterial stiffness: a systematic review and metaanalysis. J Am Coll Cardiol. 2010; 55(13):1318-1327.

7. Nishijima T, Nakayama $\mathbf{Y}$, Tsumura $\mathbf{K}$, Yamashita N, Yoshimaru K, Ueda $H$. Pulsatility of ascending aortic blood pressure waveform is associated with an increased risk of coronary heart disease. Am J Hypertens $2001 ; 14$ : 469-73.

8. Safar ME, Blacher J, Pannier B, Guerin AP, Marchais SJ, Guyonvarc'h PM. Central pulse pressure and mortality in end-stage renal disease. Hypertension 2002; $39: 735-8$.

9. Yammine M., Itagaki S., Pawale A., Toyoda N., Reddy R. SYNTAX score may predict the severity of atherosclerosis of the ascending aorta. Journal of thoracic disease 2017, 9 (10) : 3859.

10. Durmuş G., Belen E., Bayyigit A., Kalyoncuoğlu M., Can M. The Relationship between Inter-Arm Blood Pressure
Difference and Coronary Artery Disease Severity Calculated by the SYNTAX Score. International Journal of Hypertension 2018; $1-5$.

11. Senthong V, Kukongviriyapan U, Settasatian N, Settasatian C, Komanasin N. Low diastolic blood pressure is associated with a high atherosclerotic burden in patients with obstructive coronary artery disease. Cardiology Journal 2018, 25 (3): 345-352.

12. Gu G, Cui W, Feng X, Liu F, Xie RQ, Lu J. Fractional systolic and diastolic pressures act as predictors of coronary artery disease. Blood Press 2012; 21 (3) : 197-201.

13. Jankowski P, Kawecka-Jaszcz K, Bryniarski L, Czarnecka D, BrzozowskaKiszka M, Pośnik-Urbańska A. Fractional diastolic and systolic pressure in the ascending aorta are related to the extent of coronary artery disease. Am J Hypertens 2004; 17 (8) : 641-646.

14. Nakayama Y, Hayashi T, Yoshimaru K, Tsumura K, Ueda $\mathbf{H}$. Low fractional diastolic pressure in the ascending aorta increased the risk of coronary heart disease. $\mathrm{J}$ Hum Hypertens 2002; 16:837-841.

\section{Cite This Article}

Ghoniem, S., radwan, H., naas, H. Relationship between blood pressure indices and severity of coronary atherosclerosis. Zagazig University Medical Journal, 2021; (29-37): -. doi: 10.21608/zumj.2019.11362.1180 